\title{
MODEL DIALOG IMAJINER ENTAS-ENTAS UNTUK MENGKOMUNIKASIKAN KRISTUS KEPADA MASYARAKAT TENGGER
}

\author{
Daniel Fajar Panuntun, Jimmi Pindan Pute, Lisdayanti Anita Mangalik \\ Sekolah Tinggi Agama Kristen Negeri Toraja \\ daniel_fp@stakntoraja.ac.id
}

\begin{abstract}
Indonesia has a diversity of cultures, and each culture has its characteristics, and these cultures cannot be eliminated. The Tengger tribe is one of the regions that have a privilege with its culture called entas-entas, this culture is a ritual that is held to commemorate the death and to ask the Supreme Court so that the spirits who have died get a right place. Christianity needs to have a mission to communicate Christ to the Tengger Tribe. The mission can be carried out using apologetic dialogue. The method used in this study is a qualitative approach to ethnographic and theological research. Data collection uses literature studies and Bible studies. The apologetic dialogue is based on the conversational theory of evangelism from Geisler. The apologetic dialogue also refers to the God and Culture theory of Richard Neighbor. The apologetic dialogue is arranged in an imaginary conversation that can be developed and practiced by every believer. The purpose of this writing is to obtain an imaginary dialogue model as a model for communicating Christ to the Tengger community. The apologetic dialogue that was produced was in the form of 12 items of questions and directing models. The results of this study are expected to be an effective pre-evangelistic dialogue reaching people who live the culture, especially the Tengger people.
\end{abstract}

Keywords: Culture, Tengger Tribe, Entas-entas ceremonies, Imaginary Dialogue, Apologetics.

\begin{abstract}
Abstrak. Indonesia memiliki keragaman budaya dan setiap budaya memiliki ciri khas masing-masing dan budaya-budaya tersebut tidak bisa di hilangkan. Suku Tenggeradalah salah satu daerah yang memiliki keistimewaan dengan budayanya yang disebut entas-entas, Budaya ini merupakan ritual yang diadakan untuk memperingati kematian dan untuk memohon kepada Sang Maha Agung agar arwah yang telah meninggal mendapat tempat yang baik. Agama Kristen perlu memiliki misi untuk mengkomunikasikan Kristus kepada Suku Tengger. Misi tersebut dapat dilakukan dengan menggunakan dialog apologetik. Metode yang digunakan penulis dalam penelitian menggunakan pendekatan kualitatif dengan jenis penelitian etnografi dan teologis. Pengumpulan data menggunakan studi literatur dan studi alkitab. Dialog apologetis disusun berdasarkan teori conversational evangelism dari Geisler. Dialog apologetik juga mengacu pada teori God and Culture dari Richard Neighbour. Dialog apologetik yang disusun dalam suatu dialog imajiner yang dapat dikembangkan dan dipraktikan oleh setiap orang percaya. Tujuan penulisan ini adalah memperoleh Model Dialog imajiner sebagai model untuk mengkomunikasikan Kristus pada masyarakat Tengger. Dialog apologetis yang dihasilkan berupa 12 butir pertanyaan model bertanya dan mengarahkan. Hasil dari penelitian ini diharapkan dapat menjadi suatu dialog prapenginjilan yang efektif menjangkau masyarakat yang menghidupi kebudayaan terkhusus masyarakat Tengger.
\end{abstract}

Kata kunci: Budaya, Suku Tengger, Tradisi Entas-entas, Dialog Imajiner, Apologetika. 
Indonesia adalah negara yang sangat unik di mata dunia karena memiliki ciri-ciri khusus yang tidak dimiliki oleh negara lain, di antaranya adalah keadaan masyarakat yang majemuk yang terdiri dari bermacammacam suku, ras, agama, bahasa dan budaya. Menurut sensus penduduk tahun 2010, perkembangan penduduk Indonesia saat ini mencapai jumlah 237.556.363 jiwa. (Munandar, 2014), yang menempatkan Indonesia pada urutan keempat di dunia setelah Cina, India dan Amerika Serikat. Beragam suku bangsa hidup berdampingan dengan latar belakang kehidupan yang berbeda. Kondisi geografis tempat tinggal yang berbeda tersebut menjadikan masyarakat di Indonesia memiliki kehidupan yang beraneka ragam yang dipengaruhi oleh budaya masing-masing sebagai warisan dari tiap generasi sebelumnya. (Widiastuti, 2013).

Berbicara mengenai kebudayaan, maka dapat dikatakan bahwa setiap daerah di Indonesia memiliki kebudayaan dan adat yang diakui oleh masyarakat yang ada di daerah itu sendiri. Kebudayaan tersebut merupakan hasil cipta, rasa dan karsa manusia dalam memenuhi kebutuhan hidupnya yang kompleks yang mencakup pengetahuan, keyakinan, seni, susila, hukum adat, serta setiap kecakapan dan kebiasaan yang dilakukan dalam suatu masyarakat. Setiap kebudayaan tersebut memiliki tradisi upacara keagamaan berdasarkan masing-masing suku. Upacara keagamaan tersebut ada yang bersifat ritual dan ada yang bersifat seremonial. Tindakan agama terutama ditampakkan dalam upacara ritual, pola peribadatan (ritualitas) pada dasarnya merupakan 
simbolis dalam dimensi keyakinan diri terhadap sesuatu yang dianggap agung, dan dapat dikatakan bahwa ritual agama merupakan agama dalam tindakan. (Nugroho, 2019).

Pegunungan Tengger, dengan kawah Bromo yang terkenal dengan puncak yang luasnya $10 \mathrm{Km}^{2}$, merupakan perpaduan antara lembah dengan ngarai serta panorama yang menakjubkan dengan hamparan lautan pasir seluas $50 \mathrm{Km}^{2}$. (Yuliati, 2011). Kawasan wisata itulah yang memiliki daya tarik luar biasa bagi masyarakat luar dan merupakan tempat berdiam masyarakat dengan tradisi unik yang disebut masyarakat Tengger. Masyarakat Tengger adalah sebuah komunitas yang masih memegang unsur-unsur tradisi. Upacara Entas-entas, Praswala Gara, dan Pujan Kapat merupakan contoh tradisi yang masih dilakukan masyarakat Tengger sampai saat ini. (Ambayoen, 2006a). Tradisi Entas-entas sendiri merupakan ritual yang diadakan untuk memperingati kematian dan untuk memohon kepada Sang Maha Agung agar arwah yang telah meninggal mendapat tempat yang baik. (Batoro, 2002).

Bagaimana jika fakta tradisi yang unik dari masyarakat gunung Tengger ini mendorong penulis untuk membuat suatu riset mengenai dialog apologetis yang tepat dengan tradisi masyarakat Tengger dan dikhususkan pada tradisi entas-entas. Strategi misi perlu dikembangkan untuk menjangkau berbagai kalangan di Indonesia. Kalangan-kalangan tersebut dapat berupa kalangan penduduk desa maupun mereka yang setia dalam melakukan tradisi kebudayaan. (Butar-butar, 2020). 
Berdasarkan kenyataan tersebut perlu adannya suatu fokus penelitian untuk menjangkau masyarakat Tengger agar mereka dapat mengenal Kristus. Hal tersebut dapat dilakukan dengan menggunakan model dialog imajiner apologetik sebagai pra-penginjilan.

Model pra-penginjilan menggunakan konsep dialog apologetika. Dialog apologetika merupakan dialog mengenai pertanggungjawaban iman didasari dari 1 Petrus 3:14-15. Dialog apologetika mempertanggungjawabkan iman Kristen dengan lemah lembut kepada setiap tuduhan-tuduhan yang diarahkan kepadanya. (McGrath, 2017). Konsep tersebut yang akan menjembatani masyakat Tengger untuk dapat mengenal karya keselamatan yang dari Kristus. Berita Injil dapat di sampaikan dengan menggunakan jembatan yang tepat yaitu model dialog imajiner apologetis.

Berdasarkan fokus kajian tersebut dibuat rumusan masalah penelitian yaitu, bagaimana model dialog imajiner yang digunakan sebagai model untuk mengkomunikasikan Kristus pada masyarakat Tengger? Tujuan penelitian ini adalah untuk menemukan model dialog imajiner sebagai model untuk mengkomunikasikan Kristus pada masyarakat Tengger. Manfaat dari penelitian ini adalah: Pertama sebagai kajian praktika Misi Kristen melalui model dialog apologetik sebagai prapenginjilan. Kedua, menolong setiap orang percaya untuk terus bermisi sesuai dengan konteks yang tepat dan jembatan komunikasi yang tepat. Ketiga, mengenalkan Kristus di berbagai konteks kebudayaan. 


\section{METODE PENELITIAN}

Penelitian ini menggunakan pendekatan kualitatif (Lumintang, 2016) karena merupakan studi ekplorasi terhadap kebudayaan dan pendekatan Alkitabiah melalui teknik apologetika. Jenis studi pada penelitian ini menggunakan penelitian etnografi (Sugiyono, 2015) Penelitian etnografi memberikan deskripsi tentang tradisi entas-entas dari kebudayaan Tengger. Jenis penelitian kedua yang dipakai adalah penelitian teologis (Lumintang, 2016) Pengumpulan data melalui tiga proses yaitu pertama, mengumpulkan data berkaitan dengan kebudayaan Tengger dan secara khusus pada tradisi entas-entas melalui studi literatur. Kedua mencari tinjauan Alkitab mengenai Apologetika Kristen dalam mengomunikasikan Kristus melalui studi literatur berdasarkan pandangan tokoh. Ketiga melalukan analisis interaktif (Miles \& Huberman, 1982) terhadap kajian tersebut untuk menyusun model dialog imajiner. Analisis interaktif dilakukan dengan menyajikan data etnografi tradisi entas-entas dan apologetika Kristen untuk kemudian dilakukan reduksi sesuai dengan judgement peneliti sebagai pertimbangan penarikan interpretasi. Model interpretasi yang dihasilkan menjadi bahan pertimbangan rekomendasi dalam pembuatan model dialog Imajiner.

\section{Masyarakat Tengger}

Masyarakat Tengger adalah merupakan penduduk asli Jawa, yang menempati wilayah lereng pegunungan Bromo, Tengger, Semeru, Jawa Timur yang sudah ada sebelum zaman kerajaan Majapahit berdiri. (YPB 
Wiratmoko, 2005). Masyarakat tersebut dikenal sebagai masyarakat suku, berpenduduk lokal, dengan bentuk kehidupan yang masih tradisional, dan sifat kepercayaan yang masih tradisional. Mereka masih memegang teguh adat budaya atau kepercayaan leluhurnya. Agama dan kepercayaan mempunyai andil besar dalam perkembangan suku Tengger. Kebanyakan warganya adalah Pertapa dan Brahmana yang lebih suka dan senang untuk hidup dengan lingkungannya. Masyarakat suku Tengger membentuk aturan adat yang unik. (Batoro, 2002).

Dalam adat masyarakat Tengger ada ritual yang dinamakan ritual entas-entas. Ritual entas-entas dimaksudkan untuk menyucikan arwah leluhur agar sempurna untuk memasuki alam langit atau disebut alam kelanggengan.Tradisi entas-entas merupakan salah satu tradisi yang sering dilakukan oleh masyarakat Tengger di Malang, tepatnya di Desa Tengger Ngadas. Acara entas-entas merupakan upacara sakral yang dilakukan untuk mengentaskan roh leluhur melalui aturan adat yang berlangsung selama 3 sampai 4 hari. Acara entas-entas juga dilengkapi dengan sesajen, tumpeng, gedang kayu, nasi, ayam panggang, kupat lepet, bayu suci, ditambah ongkek yang meliputi beberapa tumbuhan misalnya daun pandan, bunga soka, piji, alang-alang, tebu, pisang, beras, ayam dan bebek. Tradisi ini dilakukan untuk acara kematian. Entas-entas sendiri diartikan gambaran dari meluhurkan atau mengangkat derajat leluhur yang sudah meninggal agar mendapat tempat yang baik dialam arwah. Makna yang terdapat dalam entas-entas ini yaitu untuk 
mengembalikan kembali unsur-unsur penyusun tubuh manusia. unsurunsur tersebut ialah tanah, kayu, air, dan panas. Makna yang dapat diambil dari tanah adalah bahwa setiap manusia yang meninggal akan dikubur dalam tanah; makna untuk kayu yaitu bahwa kayu ditancapkan atau ditanam sebagai nisan di atas kubur orang yang telah meniggal. (Batoro, 2002) Berdasarkan hal-hal tersebut masyarakat Tengger merupakan masyarakat yang sangat menghormati roh-roh para leluhur. Upacara entas-entas ditujukan sebagai penghargaan terhadap orang atau keluarga yang telah meninggal.

Entas-Entas adalah sebuah prosesi upacara adat kematian masyarakat Tengger. Dalam tradisi Jawa biasa disamakan dengan acara nyewu (upacara seribu hari setelah kematian) meskipun pelaksanaannya tidak tepat di hari keseribu setelah kematian. Dalam tradisi masyarakat Hindu Bali dinamakan Ngaben (upacara pembakaran mayat). Hanya saja jika dalam masyarakat Bali yang dibakar adalah kerangka orang yang sudah meninggal, maka dalam tradisi masyarakat Tengger yang dibakar adalah petra, sebuah boneka yang dibuat dari kumpulan daun-daunan, ilalang dan bunga. Petra ini menjadi tempat bagi roh orang-orang yang sudah meninggal yang akan dientas. (Ambayoen, 2006b) Sesudah dimandikan dengan air yang dimantrai oleh dukun, mayat orang meninggal lalu dikafani kain putih tiga lapis, kemudian diusung dengan ancak yang terbuat dari bambu, dikubur membujur ke timur dan dengan posisi terlentang. Selanjutnya diadakan upacara "misahi", yaitu perpisahan 
antara orang yang meninggal dengan keluarganya, dipimpin seorang dukun. Selanjutnya setelah 44 hari atau lebih diadakan Upacara "EntasEntas". Upacara ini dimaksudkan untuk memohon ampun kepada Sang Maha Agung agar arwah almarhum yang masih "Nglambrang" (melayanglayang tak menentu) segera dapat masuk surga. Pada upacara entasentas ini dibuat boneka yang terbuat dari dedaunan, bunga kenikir dan janur kuning yang menggambarkan jasad almarhum. Boneka tersebut disebut petra. Petra diberi pakaian dari pakaian asli almarhum yang dientas. Banyaknya petra yang dientas juga menurut jumlah orang yang meninggal. (Savitri, 2010). Entas-entas yang dilakukan penuh makna dan juga melibatkan berbagai proses yang harus dijalankan dengan setia serta membutuhkan berbagai kelengkapan-kelengkapan untuk prosesi ini. Hal ini merupakan keunikan tersendiri dalam kebudayaan masyarakat Tengger yang perlu untuk terus dilestarikan.

\section{Apologetika Kristen}

Apologetika merupakan IImu pengetahuan yang mengajarkan tentang bagaimana cara memberikan pemahaman dari apa yang dipercayai/diyakini seseorang secara efektif serta mampu mempertahankan dan mempertanggungjawabkannya. (McGrath, 2017). Apologetika itu adalah ilmu yang mengajar orang Kristen dalam memberi pertanggungjawaban tentang pengharapannya sehingga berfokus pada pribadi apologis yang bersangkutan erat. Apologetika Kristen merupakan sebuah usaha untuk memberikan pemahaman mengenai bukti-bukti untuk 
membuktikan bahwa apa yang terdapat dalam kitab suci itu benar adanya. (Tanudjaja, 2018). Apologetika merupakan suatu kemampuan yang harus dimiliki orang percaya untuk mengomunikasikan imannya ke dalam berbagai aspek kehidupannya. Apologetika dapat digunakan sebagai prapenginjilan dalam rangka mengomunikasikan Kristus ke dalam berbagai budaya ataupun konteks yang dihadapi.

Aplogetika Kristen dalam mengomunikasikan Kristus merupakan sebuah usaha untuk melayani Allah dengan melakukan mandat dari 1 Petrus 3:15-16, yaitu: bagaimana seorang Kristen mempertanggungjawabkan pengharapannya. (Frame, 2009). Setiap Pribadi yang terpanggil untuk mengomunikasikan Kristus tidak harus melalui percakapan, melainkan dapat digambarkan melalui karakter dan cara hidup: cara berpikir, berperilaku, serta cara berbicara. (Tanudjaja, 2018). Apologetika dapat digunakan dengan berbagai bentuk kontekstual yang ada menyesuaikan permasalahan dan budaya yang dihadapi oleh para para komunikator Injil. Setiap komunikator harus dapat secara kreatif menggunakan berbagai sumber daya yang ada untuk mengomunikaskan Kristus.

Apologetika Kristen yang baik hendaknya adalah apologetika yang bersumber dari kebenaran Firman Tuhan. (McGrath, 2017). Para apologet sebagai pelaksana apologetika harus benar-benar mengenal dan mengetahui kebenaran Firman Tuhan. Komunikasi dan proses kognisi kebenaran Firman Tuhan dapat dilakukan dalam pemuridan kontekstual 
Kristen. (Haryono \& Panuntun, 2019). Pemuridan kontekstual juga memiliki berbagai sisi positif untuk mendukung kehidupan para apologet, di antaranya: para apologet dapat mengomunikasikan Kristus akan tetapi juga sadar akan nilai-nilai kebangsaannya. (Panuntun \& Paramita, 2019). Apologet juga dapat menggunakan kemampuan konseling untuk berkomunikasi dengan audien dengan menjawab permasalahan yg dialami. (Yuliati \& Yemima, 2019). Apologet juga dapat menggunakan jembatan budayawi seperti kebudayaan Jawa untuk mengomunikasikan Kristus. (Kawangmani, 2019), Jembatan warna merah untuk mengomunikasikan Kristus dalam kebudayaan Tionghoa (Aliyanto \& Sari, 2019), berapologia dalam konteks era disrupsi (Panuntun, 2019), dan berbagai skill atau kecakapan yang harus dimiliki oleh seorang apologet lainnya. Kecakapan yang terutama adalah pengetahuan akan Firman Tuhan dan kecakapan dalam menganalisa konteks yang dihadapi.

Pengembangan apologetika untuk mengomunikasikan Kristus salah satunya dikembangkan oleh Norman dan David Geisler. Produk apologetika yang dikembangkan disebut dengan Conversation Evangelism yang merupakan bentuk mengomunikasikan Kristus dengan penekanan pada pra-pengijilan. Sifat pelaksanaan dalam mengomunikasikan Kristus didasari dari "Penginjilan adalah Proses". Produk ini disebut juga sebagai seni dalam bertanya. Conversation Evangelism terdiri atas empat percakapan utama yang ingin dibangun bersama dengan orang yang belum percaya. Pertama, percakapan yang mendengarkan. Kedua, 
percakapan yang memperjelas. Ketiga, perca-kapan yang menyingkapkan. Keempat, pertanyaan yang membangun. Keempat macam percakapan ini merupakan komposisi utama Conver-sational Evangelism. Conversational Evangelism merupakan seni ber-tanya tanpa mebuat orang merasa diserang. (Geisler \& Geisler, 2010). Conversational Evangelism merupakan salah satu produk yang dapat dikembangkan untuk membuat dialog-dialog apologetik kepada seluruh kebudayaan yang ada di dunia. Pertanyaan-pertanyaan yang dilontarkan bukanlah suatu pertanyaan yang bernada memaksa akan tetapi adalah percakapan biasa yang menolong setiap orang dengan tenang, santai, dan tanpa kecurigaan untuk saling berkomunikasi.

Keempat macam percakapan Conversational Evangelism dikategorikan ke dalam tipe percakapan: pemusik, pelukis, arkeolog dan ahli bangunan. Sebagai pemusik, apologet berusaha untuk mau mendengarkan secara lebih hati-hati serta menemukan nada-nada sumbang yang dinyanyikan oleh orang. Sebagai pelukis, apologet ingin melukiskan sebuah gambaran dengan menggunakan pertanyaanpertanyaan untuk membantu orang bercermin dalam terang kebenaran yang sejati. Sebagai arkeolog, apologet ingin menggali sejarah dan menyingkapkan hambatan apa yang sebenarnya membelenggu. Sebagai ahli bangunan, apologet ingin membangun jembatan menuju Injil. Memahami bagaimana membangun empat macam percakapan ini dengan setiap kebudayaan dan pribadi yang belum percaya seraya mengisi 
keempat peran kunci tersebut merupakan langkah yang penting diambil jika setiap apologet berkomitmen untuk menolong orang lain mengambil keputusan mengikut Kristus. (Geisler \& Geisler, 2010). Produk model komunikasi Conversational Evangelisme merupakan suatu terobosan sehingga dapat digunakan secara efektif untuk menyelamatkan setiap manusia yang belum percaya kepada Tuhan Yesus. Model ini dapat digunakan sebagai acuan dalam membuat dialog-dialog apologetik dengan tujuan untuk mengenalkan Kristus kepada semua orang yang ada di dunia ini.

Model dialog apologetik ini dapat digunakan untuk menyampaikan kabar baik. Model dialog apologetik bisa dilakukan lintas budaya. Pelaksanaan dialog apologetik lintas budaya sesuai dengan pemikiran dari Richard Neighbour. Kristus datang bukan untuk mengubah budaya setempat. Kristus yang diperkenalkan merupakan suatu bentuk transformasi dalam hati setiap orang percaya. Orang percaya dengan masing-masing kebudayaannya akan ditransformasi oleh Roh Kudus sehingga dapat memahami mana yang baik dan mana yang buruk. Pertolongan dari Roh Kudus membuat setiap orang percaya dapat tetap menjalankan seluruh kebudayaan yang dimiliki namun dengan paradigma baru dari Roh Kudus. Roh Kudus terus membimbing agar setiap orang percaya dapat hidup benar dalam menjalankan setiap kebudayaannya masing-masing karena adanya paradigma Kristus dalam hati setiap orang percaya. (Niebuhr, 1951) Berdasarkan hal ini, dalam mengabarkan kabar 
baik dan kebudayaan asal tidak ada kontradiksi sedikitpun. Keduanya dapat berjalan simultan oleh karena pertolongan Roh Kudus yang memampukan setiap orang percaya untuk mengalami transformasi secara ilahi.

\section{HASIL}

\section{Model Dialog Imajiner Entas-Entas Untuk Mengkomunikasikan}

\section{Kristus Kepada Masyarakat Tengger}

Prinsip yang digunakan adalah menggunakan prinsip teologi kontekstualisasi. Prinsip teologi kontekstualisasi menggunakan model trialektis. Metode trialektis yang digunakan adalah :

- Pemberita: memahami teks Firman dalam konteks Hebraic-helenistic.

- Pemberita: memahami World View dari penerima injil (untuk menemukan sintesis) bagaimana kira-kira njil dilihat oleh penerima dan bagaimana menyampaikan.

- Pemberita menyampaikan Firman.

- Refleksi Penerima atas penerimaan injil. (Tomatala, 1993).

- Prinsip teologi kontekstualisasi bertujuan mengenali kebudayaan setempat maka diperoleh sintesis untuk mengkomunikasikan Kristus melalui dialog apologetis.

Metode yang digunakan merupakan dialog apologetis untuk mengabarkan kabar baik. Dialog apologetis ini ditujukan bukan untuk menghilangkan kebudayaan awal akan tetapi untuk mengenalkan Kristus secara kontekstual. Dialog imajiner menghargai setiap hasil kebudayaan 
yang dihasilkan oleh budaya-budaya setempat. Dialog imajiner ini membawa setiap orang percaya selangkah lebih dekat dengan pengetahuan mengenai Kristus sehingga setiap orang dapat percaya dan mengenal Kristus sebagai Tuhan dan Juruselamat.

Dialog imajiner yang dihasilkan menggunakan prinsip dialog apologetika. Dialog apologetika yang memberikan jawaban untuk setiap tuduhan-tuduhan mengenai kekristenan dengan lemah lembut dan penuh tanggung jawab. Jawaban-jawaban tersebut dibentuk dalam suatu rangkaian pertanyaan dalam susunan dialog. Tujuan utamanya adalah memproklamasikan Kristus.

Sasaran dari dialog ini adalah salah satu hasil kebudayaan masyarakat Tengger yaitu kebudayaan entas-entas. Hal ini digunakan sebagai jembatan komunikasi untuk mengabarkan Kristus. Kebudayaan ini juga tidak akan digeser atau dihilangkan oleh Kristus akan tetapi digunakan dalam rangka mengomunikasikan Kristus.

Dialog apologetis tersebut dibuat dalam garis besar dialog imajiner sebagai berikut:

1. Apa tujuan hidup saudara?

2. Apa keistimewaan Gunung Bromo dan ciri khas masyarakat Tengger?

3. Masyarakat tengger sangat istimewa dalam memperingati kematian, dan saya mengetahui nama upacaranya entas-entas, apakah keistimewaan entas-entas dan bagaimana prosesinya?

4. Apa tujuan dari prosesi tersebut? 
5. Bagaimana anda memahami entas-entas dalam pemikiran anda?

Bagian ini ditujukan untuk mengetahui pemahaman mengenai kematian di kalangan masyarakat Tengger menurut pengertiannya sendiri dan mencoba mendengarkan nada-nada sumbang dari jawaban yang diberikan oleh responden.

6. Menurut anda bagaimana akibat dari seseorang yang tidak melalukan prosesi entas-entas?

7. Apabila dalam kematian terjadi proses reinkarnasi, apakah reinkaranasi tersebut harus menunggu sampai entas-entas dilakukan? Dan bagaimanakah reinkarnasi yang pertama jika perputaran hidup tersebut dilakukan dalam rangka mencapai kesempuranaan?

8. Sesungguhnya siapakah yang memberikan jaminan bahwa entasentas membuat roh leluhur menjadi nyaman?

Pada bagian ini apologet mencoba melukiskan audien mengenai suatu kebenaran dari keragu-raguan akan pandangannya sendiri.

9. Menurut pengetahuan saya, entas-entas dilakukan oleh setiap masyarakat Tengger agar roh yang meninggal bisa diterima di Surga tanpa memandang dari kalangan apapun, apakah benar demikian?

10. Apakah benar melalui entas-entas roh dapat langsung ke sorga atau harus mengalami renkarnasi dulu? Kalau mengalami renkarnasi memerlukan berapa kali entas-entas? Bagaimana entas-entas tetap dilakukan jika mereka dilahirkan keluar dari luar masyarakat tengger? 
Pada bagian ini apologet bertujuan untuk mengentahui halangan-halangan sejarah dan menggali lebih dalam mengenai kebudayaan audiens.

11. Apakah saudara ingin memahami entas-entas sebagai bentuk ucapan syukur atas kepastian masuk surga?

12. Jika demikian apakah saudara ingin mengerti tentang sang Juruselamat dan kepastiannya mengenai sorga sehingga entas-entas kini menjadi upacara syukur kepastian masuk surga?

Pada bagian ini apologet mencoba untuk membangun jembatan komunikasi kepada kebenaran injil.

\section{PEMBAHASAN}

Dialog imajiner tersebut terdiri atas 12 pertanyaan yang tidak ditanyakan secara langsung. Komunikator harus secara kreatif dapat membuat audiens bertanya-tanya mengenai keunikan Kristus. Pertanyaan 1-5 dapat ditanyakan dalam 3 kesempatan berbeda dalam seni bertanya dimana komunikator ingin mendengarkan segala nada sumbang dalam kepercayaan dari masing-masing pelaku kebudayaan entas-entas. Hal ini juga berlaku pada pertanyaan untuk melukiskan yaitu pertanyaan nomor 6-8, pertanyaan untuk mengentahui halangan komunikan yaitu nomor 810, dan pertanyaan untuk menyusun suatu jembatan komunikasi yaitu nomor 11-12. Dialog ini digunakan sebagai pra-penginjilan sehingga setiap orang dapat mengerti keunikan Kristus. Langkah selanjutnya apabila dialog imajiner membawa komunikan tertarik pada kebenaran 
Kristus adalah langkah untuk mengenalkan komunikan terhadap injil. Pada akhirnya komunikan dapat menerima berita Injil akan tetapi tidak kehilangan konteks budayanya sebagai seorang masyarakat Tengger yang melakukan tradisi entas-entas.

Dialog imajiner merupakan dialog yang digunakan secara dinamis sebagai pra-penginjilan. Para Penginjil dapat secara dinamis bertemu dengan konteks dan menemukan jembatan komunikasi dari setiap kebudayaan dan mencoba mengungkap letak Kristus di dalam kebudayaan tersebut. Kristus dalam kebudayaan menjadi jembatan komunikasi yang digunakan sebagai titik awal dalam memperkenalkan Injil. Setiap masyarakat yang memiliki kebudayaan tersebut menyadari bahwa Yesus adalah hal yang istimewa dan diharapkan tertarik untuk semakin mengetahui mengenai pengetahuan tentang Yesus yang terdapat dalam Injil.

Konsep ini merupakan konsep perpaduan pra-penginjilan yang sangat ramah terhadap kebudayaan setempat. Dialog imajiner berusaha melakukan kontekstualisasi dengan memberikan makna baru dalam kebudayaan tersebut dalam melakukan setiap prosesi-prosesi adatnya. Berdasarkan hal tersebut keberagaman Indonesia yang kaya akan budayanya tidak akan hilang namun setiap mereka yang setia untuk menghidupi kebudayaan setempatnya dapat mengenal Kristus melalui dialog imajiner ini. 
Dialog imajiner entas-entas dikembangkan dengan memperhatikan konteks kebudayaan setempat sehingga model dialog ini merupakan model dialog yang sangat ramah dalam memperkenalkan Injil dan dengan jelas memberikan posisi Kristus dalam kebudayaan. Model dialog imajiner ini dapat diaplikasikan dalam percakapan sehari-hari dan dikembangkan oleh penginjil dengan fokus utama menghargai kebudayaan setempat dan menemukan Kristus dalam kebudaaan tersebut. Pada akhirnya dialog imajiner ini akan memperkenalkan Yesus dan setiap orang dapat ditransformasi untuk mengetahui keselamatan yang kekal yang berasal dari Kristus.

Dialog imajiner merupakan solusi misi dan penginjilan yang tepat dan kontekstual di negara Indonesia. Hal ini merupakan misi cinta damai tanpa merusak kebudayaan asal. Teknik ini memperkenalkan Yesus secara harmonis sehingga memujudkan ketentraman bagi masyarakat berbudaya di seluruh nusantara terkhusus pada konteks masyarakat Tengger dengan tradisi entas-entasnya. Model dialog ini merupakan model dialog kreatif yang patut dikembangkan untuk menjangkau setiap kebudayaan-kebudayaan yang terdapat di Indonesia dengan ramah. Pada akhirnya dialog imajiner ini merupakan dialog pra-penginjilan yang ramah bagi masyarakat berbudaya di Indonesia.

\section{KESIMPULAN}

Penelitian ini menghasilkan suatu dialog imajiner yang terdiri atas 12 pertanyaan mendasar mengenai dialog imajiner apologetika Kristen 
terhadap kebudayaan entas-entas masyarakat Tengger. Hal ini mendorong setiap orang percaya memiliki keberanian untuk mengabarkan Kristus keberbagai kebudayaan dengan menggunakan seni bertanya. Kristus tidak akan mengubah kebudayaan asal akan tetapi akan mentransformasi hati setiap orang percaya sehingga dapat memaknai kebudayaan asal dengan paradigma baru yang benar.

Saran dari penelitian ini adalah untuk dibuat suatu riset kuantitatif yang membuktikan dialog imajiner ini. Riset lanjutan dapat berupa studi efektifitas, kepuasan, dan pengaruh antara komunikasi Kristus terhadap penerimaan berita Injil.

\section{DAFTAR PUSTAKA}

Aliyanto, D. N., \& Sari, S. K. (2019). MAKNA WARNA MERAH DALAM TRADISI ETNIS TIONGHOA SEBAGAI JEMBATAN KOMUNIKASI UNTUK MEMPERKENALKAN MAKNA DARAH YESUS. Gamaliel:Teologi Praktika, 1(2), 93-103.

Ambayoen, M. A. (2006a). Pola Komunikasi Masyarakat Tengger Dalam Sosialiasi Tradisi entas-entas, Praswala gara, Dan pujan Kapat (Studi Kasus di Desa Ngadisari, Kecamatan Sukapura, Kabupaten Probolinggo). Institut Pertanian Bogor.

Ambayoen, M. A. (2006b). Pola Komunikasi Masyarakat Tengger dalam Sosialisasi Tradisi Entas-entas Prasawala Gara dan Pujan Kapat. Institut Pertanian Bogor.

Batoro, J. (2002). Keajaiban Bromo Tengger Semeru. Tim UB Press.

Butar-butar, G. M. (2020). Strategi Misi Pedesaan Yang Relevan Dan Alkitabiah Di Kabupaten Toba Samosir. Jurnal Gamaliel: Teologi Praktika, 2(1), 38-53. https://doi.org/10.38052/gamaliel.v2i1.47

Frame, J. (2009). Apologetika bagi Kemuliaan Allah. Penerbit Momentum (Momentum Christian Literature.

Geisler, N., \& Geisler, D. (2010). Conversational Evangelism. Yayasan 
Gloria.

Haryono, T., \& Panuntun, D. F. (2019). Andil pemuridan kontekstual yesus kepada petrus yakobus dan yohanes terhadap keterbukaan konseling mahasiswa pada masa kini. Gamaliel: Teologi praktika, 1(1), 12-25.

Kawangmani, S. (2019). POLA APOLOGETIKA KONTEKSTUAL UNTUK MEMBERITAKAN KABAR BAIK KEPADA SUKU JAWA WONG CILIK. Gamaliel: Teologi praktika, 1(2), 278-279.

Lumintang, S. I. D. A. L. (2016). Theologia penelitian dan Penelitian Theologis science-ascience serta metodologinya. Geneva Insani Indonesia.

McGrath, A. (2017). Apologetika Dasar. Literatur SAAT.

Miles, M. B., \& Huberman, A. M. (1982). Qualitative Data Analysis: A Sourcebook of New Methods. SAGE publications.

Munandar, Y. (2014). Analisis Persebaran Rumah Tangga Di Indonesia. Budi Utama.

Niebuhr, H. R. (1951). Christ and Culture. Harper and Row.

Nugroho, W. (2019). Mmemperluas Horizon Agama dalam Konteks Indonesia. Yayasan Taman Pustaka Kristen Indonesia.

Nurudin, Sudarwo, V. S. D., \& Faturrohman, D. (2003). Agama Tradisional. Lkis Yoyakarta.

Panuntun, D. F. (2019). Misi Apologetika Kristen Online di Era Diruspsi. Apostolos, 2(1).

Panuntun, D. F., \& Paramita, E. (2019). HUBUNGAN PEMBELAJARAN ALKITAB TERHADAP NILAI-NILAI ( KELOMPOK TUMBUH BERSAMA KONTEKSTUAL ). Gamaliel: Teologi praktika, 1(2), 104115.

Savitri, A. (2010). Sejarah, agama, dan tradisi Suku tengger gunung bromo.

Sugiyono. (2015). Metode Penelitian dan Pengembangan (Research and Development). Alfabeta.

Tanudjaja, R. (2018). Spiritualitas Kristen \& Apologetika Kristen. Literatur SAAT.

Tomatala, Y. (1993). Teologi Kontekstualisasi (suatu pengantar). Gandum 
Mas.

Widiastuti. (2013). Analisis SWOT Keragaman Budaya Indonesia. Jurnal ilmiah WIDYA, 1(1).

YPB Wiratmoko. (2005). Cerita Rakyat dari Tengger. CV Jejak.

Yuliati, Y. (2011). Perubahan Ekologis dan Strategi Adaptasi Masyarakat di Wilayah Pegunungan Tengger. IKAPI.

Yuliati, \& Yemima, K. (2019). MODEL PEMURIDAN KONSELING BAGI ALUMNUS PERGURUAN TINGGI LULUSAN BARU (FRESH GRADUATE) YANG MENGINGKARI PANGGILAN PELAYANAN. Gamaliel:Teologi Praktika, 1(1), 26-40. 